Volume 1 Nomor 12020

http://journal.febubhara-sby.org/bharanomic ISSN: 2774-7190

haranomics

\title{
PERAN BADAN USAHA MILIK DESA (BUMDES) DALAM MENINGKATKAN POTENSI DAN KESEJAHTERAAN MASYARAKAT DESA (Studi Pada BUMDes Sumber Sejahtera, Desa Pujonkidul, Kecamatan Pujon, Kabupaten Malang, Jawa Timur)
}

\author{
* Elma Lazuardiah, Mohammad Balafif, Anggraeni Rahmasari \\ Prodi Ekonomi Pembangunan, Fakultas Ekonomidan Bisnis \\ Universitas Bhayangkara Surabaya, Indonesia
}

DOI: 10.46821/bharanomicss.v1i1.12

\begin{abstract}
Abstrak
Badan Usaha Milik Desa adalah badan usaha yang didirikan oleh Pemerintah Desa dengan modal awal bersumber dari APB Des untuk mendayagunakan segala potensi ekonomi, kelembagaan perekonomian serta potensi sumber daya alam dan sumber daya manusia dalam rangka meningkatkan kesejahteraan masyarakat desa. Penelitian ini bertujuan untuk mengetahui peran BUMDes dalam mendayagunakan potensi ekonomi lokal dengan beragam potensi yang dimiliki desa guna meningkatkan kesejahteraan ekonomi masyarakat desa serta mendorong peningkatan pendapatan asli desa. Penelitian ini bersifat lapangan, Teknik pengumpulan data yang digunakan dalam penelitian ini adalah teknik triangulasi (observasi, wawancara dan dokumentasi). Metode penelitian ini menggunakan metode penelitian kualitatif deskriptif. Hasil dari penelitian ini adalah Peran BUMDes Sumber Sejahtera dalam meningkatkan potensi dan kesejahteraan ekonomi masyarakat di Desa Pujonkidul melalui program dan unit usahanya dapat membuka lapanagan pekerjaan baru untuk warga, meningkatkan pendapatan masyarakat serta mendorong peningkatan PAD Desa.
\end{abstract}

Kata kunci: BUMDes, Potensi, Kesejahteraan Masyarakat

\begin{abstract}
:
Badan Usaha Milik Desa is agency business that was established by the Government of the village with capital beginning sourced from APB December to utilize all the potential economic, institutional economy as well as the potential source of the power of nature and the source of the power of man in order to improve the welfare of the community village . Research This aims to determine the role of BUMDes in utilizing the potential of the economy locally with a variety of potential which is owned by the village in order to improve the welfare of the economy of society villagers and encourage an increase in revenues native village. This research is a field, data collection techniques used in this study is a triangulation technique ( observation, interview and documentation ). The method of research is using the method of research qualitative descriptive. The results of this study are the role of BUMDes Sumber Sejahtera in increasing the potential and economic prosperity of the community in Pujonkidul Village through its programs and business units that can open new jobs for residents, increase community incomes and encourage increased PAD Desa.
\end{abstract}

Keywords: BUMDes, Potential, Welfare Society

*Corresponding Author:

Hal: 9-16

Email: elma14.lazuardi@gmail.com 
PENDAHULUAN

Lahirnya Undang-Undang (UU) Nomor 6 Tahun 2014 beserta turunannya membawa kabar gembira bagi desa.Dalam Undang-Undang No 6 Tahun 2014 dijelaskan bahwa desa disarankan untuk memiliki suatu badan usaha yang berguna untuk memenuhi kebutuhan masyarakat, terutama kebutuhan pokok dan tersedianya sumber daya desa yang belum dimanfaatkan, serta tersedianya sumber daya manusia yang mampu mengelola badan usaha sebagai aset penggerak perekonomian masyarakat. Dalam era otonomi juga perlu diberlakukan kebijakan yang memberikan akses dan memberikan kesempatan kepada desa untuk dapat menggali potensi baik sumber daya alam maupun sumber daya manusia yang berada dalam wilayah desa tersebut yang nantinya akan digunakan sebagai sumber pendapatan desa.

Badan Usaha Milik Desa (BUMDes) adalah badan usaha yang didirikan oleh Pemerintah Desa dengan modal awal bersumber dari APB Desa. Di Kabupaten Malang Provinsi Jawa Timur tepatnya di Kecamatan Pujon, yang memiliki 10 desa salah satunya yaitu desa Pujon Kidul. Desa dengan luas wilayah 486 Ha memiliki Badan Usaha Milik Desa yang bernama BUMDes "Sumber Sejahtera", dimana BUMDes tersebut memiliki 6 (enam) unit usaha yang dikelola BUMDes Sumber Sejahtera. Dalam pengelolaan Unit-unit usaha tersebut langsung di bawahi oleh BUMDes Sumber Sejahtera. Jenis-jenis unit usaha BUMDes Sumber Sejahtera antara lain Wisata Cafe Sawah, Parkir Wisata, Laku Pandai, TPST, Pertanian, serta HIPPAM.

Melalui BUMDes Sumber Sejahtera desa Pujon Kidul berhasil mengelola dana desa menjadi lokasi wisata yang merupakan salah satu unit usahanya. Pada tahun 2018, yang sebelumnya PADes desa Pujon Kidul hanya berkisar Rp.30-40 juta per tahun. (www.kemenkeu.go.id, 2020). Dibalik suksesnya peran BUMDes Sumber Sejahtera dalam mengelola Dana Desa untuk pembangunan Desa Wisata Pujon Kidul, terdapat beberapa permasalahan yang ditemukan antara lain kurangnya partisipasi aktif masyarakat dalam pengembangan desa wisata dikarenakan terkendala dari kurangnya motivasi masyarakat, sosialisasi, serta kesulitan masyarakat dalam mengurus perizinan terkait produk olahan khas. Di samping itu jumlah sumber daya manusia pengelola BUMDes yang memiliki kompetensi yang masih terbatas.

Berdasarkan hal tersebut diatas merupakan suatu hal yang menarik bagi penulis untuk mengkaji lebih jauh tentang peran BUMDes dalam meningkatkan potensi dan kesejahteraan masyarakat desa dengan mengangkat judul penelitian,"Peran Badan Usaha Milik Desa (BUMDes) Dalam Meningkatkan Potensi dan Kesejahteraan Ekonomi Masyarakat Desa (Studi Pada BUMDes Sumber Sejahtera, Desa Pujon Kidul, Kecamatan Pujon, Kabupaten Malang)".

\section{TINJAUAN PUSTAKA}

\section{Pengertian Peran}

Istilah peran dalam Kamus Besar Bahasa Indonesia (KBBI) memiliki arti pemain sandiwara (film), perangkat tingkah yang diharapkan dimiliki oleh orang yang berkedudukan di masyarakat. 


\section{Pengertian BUMDes}

Badan Usaha Milik Desa (BUMDes) menurut Pasal 1 Peraturan Pemerintah (PP) Nomor 43 Tahun 2014 adalah badan usaha yang seluruhnya atau sebagian besar modal dan pengelolaannya dimiliki oleh desa dan masyarakat melalui penyertaan secara langsung yang berasal dari kekayaan desa yang dipisahkan guna mengelola aset jasa pelayanan dan usaha lainnya untuk sebesar-besarnya kesejahteraan masyarakat desa.

\section{Pengertian Potensi}

Menurut Kamus Besar Bahasa Indonesia (KBBI), potensi diartikan sebagai suatu kemampuan yang mempunyai berbagai kemungkinan atau harapan untuk dikembangkan lebih lanjut, baik itu berupa kekuatan,daya ataupun kesanggupan yang diperoleh masyarakat secara langsung ataupun melalui proses yang panjang. Istilah kata potensi berasal dari bahasa Inggris "topotent"yang berarti keras atau kuat.

\section{Pengertian Kesejahteraan Masyarakat}

Menurut Undang-Undang No 11 Tahun 2009, tentang Kesejahteraan Masyarakat, kesejahteraan masyarakat adalah kondisi terpenuhinya kebutuhan material, spriritual, dan social warga negara agar dapat hidup layak dan mampu mengembangkan diri, sehingga dapat melaksanakan fungsi sosialnya.

\section{METODE PENELITIAN}

a. Lokasi dan waktu penelitian

Pada BUMDes Sumber Sejahtera Desa Pujonkidul Kecamatan Pujon Kabupaten Malang, selama 5 bulan.

b. Pendekatan penelitian

Pendekatan kualitatif

c. Metode Pengumpulan Data

Triangulasi Gabungan, Observasi, Wawancara Mendalam dan Dokumentasi.

d. Analisis Data

Pengumpulan Data, Reduksi Data, Penyajian Data, Penarikan Kesimpulan.

\section{HASIL DAN PEMBAHASAN}

\section{Peran Badan Usaha Milik Desa (BUMDes) dalam meningkatkan Potensi Desa}

Berdasarkan data yang di peroleh peneliti saat melakukan observasi lapangan, dapat dikatakan bahwa Peran BUMDes Sumber Sejahtera dalam meningkatkan potensi desa Pujonkidul sudah baik namun belum maksimal karena, BUMDes Sumber Sejahtera masih berfokus pada beberapa unit usaha antara lain unit usaha Cafe sawah, parkir, laku pandai dan pertanian sedangkan unit lainnya masih belum di kelola dan dimanfaatkan dengan baik. Maka dari itu sinergitas antara BUMDes, Pemerintah Desa serta partisipasi masyarakat sangat diperlukan demi mewujudkan Desa Pujonkidul yang mandiri, berdaya serta dapat menyejahterakan masyarakat melalui potensi lokal yang dimiliki oleh desa. 
Bharanomics

Vol. 1 No. 12020

Elma Lazuardiah dkk., Peran Badan Usaha Milik Desa (BUMDES)

\section{Peran BUMDes dalam Meningkatkan Kesejahteraan Masyarakat}

Dari hasil observasi lapangan yang dilakukan di Desa Pujonkidul. Berdasarkan hasil wawancara dengan pihak-pihak terkait, dapat dijelaskan bahwa peran Badan Usaha Milik Desa (BUMDes) Sumber Sejahtera dalammeningkatkan kesejahteraan ekonomi masyarakat sudah sangat luar biasa manfaatnya. Hal tersebut di tinjau dari program-program yang telah di lakukan oleh BUMDes seperti pelatihan, sosialisasi dan sebagainya. Selain itu, melalui unit- unit usaha yang di miliki oleh BUMDes Sumber Sejahtera masyarakat di fasilitasi dalam pemenuhan kebutuhan sehari-hari. Contohnya pada unit laku pandai masyarakat dapat melakukan kegiatan perbankan dan pembayaran listrik. Serta pada unit usaha pertanian, masyarakat diberikan pelatihan agar lebih inovatif dalam mengelola hasil tani maupun ternak guna menambah nilai ekonominya. BUMDes Sumber Sejahtera sendiri berkontribusi dalam meningkatkan pendapatan masyarakat serta mendorong peningkatan Pendapatan Asli Desa (PAD) terbukti pada tahun 2019 PAD Desa Pujonkidul sebesar Rp. 1.950.907.888.

Tabel 1

Pendapatan Masyarakat Desa Pujonkidul (Jan 2015)

\begin{tabular}{llccc}
\hline No. & Jenis Pekerjaan & Modal Awal & Penjualan & Pendapatan \\
\hline & Pertanian & - & - & Rp. 1.500 .000 \\
& Peternakan & Rp. 3.500 .000 & Rp. 11.500 .00 & Rp. 8.000 .000
\end{tabular}

Sumber: Hasil Wawancara di olah Peneliti (2020)

Tabel 2

Pendapatan Masyarakat Desa Pujonkidul (Feb2020)

\begin{tabular}{|c|c|c|c|c|}
\hline No. & Jenis Pekerjaan & Modal Awal & Penjualan & Pendapatan \\
\hline & Pertanian & Rp.1.500.000 & Rp. 4.000.000 & Rp. 2.500.000 \\
\hline & Peternakan & Rp. 6.500 .000 & Rp. 21.000.000 & Rp. 14.000 .000 \\
\hline
\end{tabular}

Sumber: Hasil Wawancara di olah Peneliti (2020)

Tabel 3

APBDes Desa Pujonkidul Tahun 2015

\begin{tabular}{lllll}
\hline No. & $\begin{array}{l}\text { Pendapatan Asli } \\
\text { Desa }\end{array}$ & $\begin{array}{l}\text { Bagi Hasil Pajak dan } \\
\text { Bagi HasilRetribusi }\end{array}$ & Dana Desa & $\begin{array}{l}\text { Bagian Dana Per- } \\
\text { kembangan (ADD) }\end{array}$ \\
\hline Rp. 40.000.000 & Rp. 15.038.343 & Rp. 400.000.000 & Rp. 183.341.720
\end{tabular}

Sumber: Hasil Wawancara di olah Peneliti (2020)

Tabel 4

APBDes Desa Pujonkidul Tahun 2019

\begin{tabular}{lllll}
\hline No. & $\begin{array}{l}\text { Pendapatan Asli } \\
\text { Desa }\end{array}$ & $\begin{array}{l}\text { Bagi Hasil Pajak dan } \\
\text { Bagi Hasil Retribusi }\end{array}$ & Dana Desa & $\begin{array}{l}\text { Bagian Dana Per- } \\
\text { kembangan (ADD) }\end{array}$ \\
\hline Rp. 1.950.907.888 & Rp. 36.334.033 & Rp.1.014.121.000 & Rp.533.622.000
\end{tabular}

Sumber: Hasil Wawancara di olah Peneliti (2020) 
Bharanomics

Vol. 1 No. 12020

EIma Lazuardiah dkk., Peran Badan Usaha Milik Desa (BUMDES)

Berdasarkan tabel di atas, dapat diketahui bahwa pendapatan masyarakat desa Pujonkidul sebelum adanya BUMDes Sumber Sejahtera dan setelah keberadaan BUMDes Sumber Sejahtera mengalami perubahan. Hal tersebut terjadi pada masyarakat yang mayoritas berprofesi pada sektor pertanian dan peternakan. Pendapatan yang di peroleh dapat di katakan cukup besar sehingga, dapat membantu meningkatkan kesejahteraan ekonomi masyarakat Desa Pujonkidul. Kontribusi yang besar juga di berikan BUMDes Sumber Sejahtera dalam mendorong peningkatan Pendapat Asli Desa (PAD).

Apabila di analisis, Peran BUMDes Sumber Sejahtera dalam meningkatkan kesejahteraan masyarakat Pujonkidul tergolong dalam teori kesejahteraan sosial menurut Friendlander yang menyatakan bahwa kesejahteraan sosial merupakan sistem yang terorganisir dari pelayanan-pelayanan dan lembaga-lembaga sosial, yang dimaksudkan untuk membantu individu-individu dan kelompok-kelompok agar mencapai tingkat hidup dan kesehatan yang memuaskan, dan hubungan-hubungan personal dan sosial yang memberi kesempatan kepada mereka untuk mengembangkan seluruh kemampuannya dan untuk meningkatkan kesejahteraan sesuai dengan kebutuhan-kebutuhan keluarga dan masyarakatnya. Artinya, BUMDes Sumber Sejahtera yang merupakan lembaga berbasis ekonomi sekaligus lembaga sosial yang bertujuan meningkatkan kesejahteraan masyarakat desa serta memupuk modal sosial.

Berikut uraian dampak dari adanya BUMDes Sumber Sejahtera dalam meningkatkan kesejahteraan masyarakat :

a. Menciptakan lapangan pekerjaan untuk masyarakat DesaPujonkidul

b. Melalui program-program pelatihan yang di lakukan BUMDes dapat memberikan wawasan serta kemampuan kepada masyarakat agar lebih inovatif dalam mengolah hasil tani maupun ternak guna menambah nilaiekonominya.

c. Menjadikan Desa Pujonkidul dikenal oleh banyak masyarakat luas dengan salah satu unit usahanya yaitu "CafeSawah".

d. Memberikan kemudahan akses untuk masyarakat dalam melakukan kegiatan transaksi perbankan melalui salah satu unitusahanya.

e. Meningkatkan produktivitas dalam kegiatan ekonomi masyarakat dan memanfaatkan aset desa Pujonkidul dengan baik.

f. Mendorong peningkatan Pendapatan Asli Desa (PAD) DesaPujonkidul.

Dari uraian di atas dapat dikatakan bahwa BUMDes Sumber Sejahtera termasuk ke dalam kategori BUMDes yang baik, hal ini dikarenakan BUMDes Sumber Sejahtera telah memberikan banyak manfaat kepada masyarakatnya. Hal tersebut selaras dengan tujuan BUMDes yang sesuai dengan Peraturan Menteri Desa dan Daerah Tertinggal Bab II Pasal 3, antara lain (1) meningkatkan perekonomian desa, (2) memanfaatkan aset desa untuk kesejahteraan masyarakat desa, (3) mengembangkan usaha masyarakat, (4) membuka lapangan pekerjaan bagi masyarakat desa, (5) meningkatkan pendapatan masyarakat dan pendapatan asli desa, dan (6) meningkatkankesejahteraan masyarakat desa. BUMDes dalam kegiatannya di samping untuk membantu penyelenggaraan pemerintah desa, juga untuk memenuhi kebutuhan masyarakat desa. BUMDes juga dapat melaksanakan peran sekaligus fungsi pelayanan jasa, perdagangan, dan pengembangan ekonomi lainnya. Peran dan 
Fungsi BUMDes bagi pemerintah desa dan masyarakat desa adalah sebagai intermediasi, pendampingan, sosial dan anggaran. (Handayati, 2009). Dari data hasil wawancara di atas BUMDes Sumber Sejahtera memiliki peran sekaligus fungsi sebagai fasilitator dan server. Berikut penjelasan mengenai fungsi BUMDes Sumber Sejahtera antara lain sebagai berikut:

1. Fasilitator, yang berarti BUMDes Sumber Sejahtera menyediakan fasilitas untuk memenuhi kebutuhan sehari-hari masyarakat desa. Hal tersebut di wujudkan dalam unit-unit usaha yang dimiliki oleh BUMDes Sumber Sejahtera. Sebagai contoh pada unit usaha laku pandai yang memfasilitasi masyarakat dalam melakukan kegiatan transaksi perbankan, pembayaran listrik dansebagainya.

2. Server, yang berarti BUMDes Sumber Sejahtera memberikan pelayanan kepada masyarakat dalam pemenuhan kebutuhan sehari-hari. Contohnya pada unit usaha HIPPAM atau air bersih yang memfasilitasi pengairan sawah masyarakatdesa.

Kesejahteraan masyarakat adalah suatu kondisi yang memperlihatkan tentang keadaan kehidupan masyarakat yang dapat dilihat dari standar kehidupan masyarakat (Badrudin dalam Widyastuti 2017;145) Dengan adanya BUMDes Sumber Sejahtera dapat mengembangkan perekonomian masyarakat Desa Pujonkidul dan mampu memberikan pelayanan yang maksimal bagi masyarakat, serta meningkatkan Pendapatan Asli Desa (PAD) sehingga berdampak pada peningkatan laju pembangunan desa dan peningkatan sumber daya masyarakat yang akhirnya bermuara pada taraf hidup masyarakat yang lebih sejahtera.

\section{Potensi Desa dalam Meningkatkan Kesejahteraan Ekonomi Masyarakat}

Dalam mengembangkan Potensi Desa BUMDes Sumber Sejahtera mengembangkan unit usaha Cafe sawah yang berorientasi pada sektor pariwisata. Hal tersebut banyak menyerap tenaga kerja yang berasal dari berbagai kalangan masyarakat desa, selain itu dengan di kembangkannya Desa Pujonkidul sebagai Desa Wisata sangat membantu pada unit usaha dalam sektor pertanian karena mayoritas masyarakat desa berprofesi sebagai petani dan buruh tani, BUMDes Sumber Sejahtera ikut andil dalam memfasilitasi kebutuhan bercocok tanam mulai dari pemenuhan kebutuhan obat organik, hingga cara pengelolaan hasil tani guna menambah nilaiekonominya.

Namun di balik itu semua masyarakat Desa Pujonkidul memiliki harapan yang besar dengan keberadaan BUMDes Sumber Sejahtera yaitu dengan lebih memaksimalkan potensi lokal Desa Pujonkidul baik dari segi sumber daya alam maupun sumber daya manusianya. BUMDes merupakan suatu badan usaha bercirikan desa yang dalam pelaksanaan kegiatannya di samping untuk membantu memenuhi kebutuhan masyarakat desa, BUMDes juga dapat melaksanakan fungsi pelayanan jasa, perdagangan, dan pengembangan ekonomi lainnya.

Pemerintah Desa Pujonkidul dalam perannya sebagai fungsi pendampingan yaitu, sebagai upaya peningkatan kapasitas usaha masyarakat desa ke depannya lebih memaksimalkan tiap unit-unit usaha yang dimiliki BUMDes Sumber Sejahtera, guna lebih memanfaatkan dengan baik potensi desa yang dimiliki agar dapat mendorong investasi masuk kedalam Desa Pujonkidul. Hal itu apabila terjadi akan memiliki manfaat bagi BUMDes Sumber Sejahtera, masyarakat serta kembali kepada pemerintah desa. 


\section{SIMPULAN}

Berdasarkan Hasil Penelitian yang dipaparkan di atas, Skripsi ini membahas mengenai Peran Badan Usaha Milik Desa (BUMDes) Dalam Meningkatkan Potensi dan Kesejahteraan Ekonomi Masyarkat Desa. dapat di tarik kesimpulan sebagai berikut: 1) Peran BUMDes Sumber Sejahtera dalam meningkatkan potensi desa Pujonkidul sudah baik namun belum maksimal karena, BUMDes Sumber Sejahtera masih berfokus pada beberapa unit usaha antara lain unit usaha Cafe sawah, parkir, laku pandai dan pertanian sedangkan unit lainnya masih belum di kelola dan dimanfaatkan dengan baik dan maksimal. 2) Peran BUMDes Sumber Sejahtera dalam meningkatkan kesejahteraan masyarakat sudah luar biasa manfaatnya sehingga mampu berkontribusi dalam peningkatan pendapatan masyarakat setelah adanya BUMDes Sumber Sejahtera dan mendorong Pendapatan Asli Desa (PAD) terbukti sebelum dan setelah pada tahun 2019 PAD Desa Pujonkidul sebesar Rp.1.950.907.888. 3) Potensi Desa dalam Meningkatkan Kesejahteraan Ekonomi Masyarakat dapat dilihat dari pemanfaatan sumber daya alam yang kemudian dikembangkan menjadi Desa Wisata Pujonkidul. Dengan di kembangkannya desa pujon kidul sebagai desa wisata dapat membuka lapangan pekerjaan baru untuk masyarakat desa.

\section{DAFTAR PUSTAKA}

ADMIN. (2017, oktober selasa). http:/www.smedev.co.id/bumdes-terbaik/. Diambil kembali dari smedev.co.id: https://www.smedev.co.id/bumdes-terbaik/, di akses pada tanggal 29 Februari 2020 pukul 20.46

Adawiyah, Robiatul. 2018. "Strategi Pengembangan Badan Usaha Milik Desa (BUMDes) Berbasis Aspek Modal Sosial (Studi pada BUMDes Surya Sejahtera, Desa Kedung Turi, Kecamatan Taman, Kabupaten Sidoarjo)". Jurnal Administrasi Negara, Kebijakan dan Manajemen Publik, Vol.6 No.3, September-Desember 2018. Fakultas Ilmu Sosial dan Politik Universitas Airlangga

Anggito, Albi dan Johan Setiawan. 2018 . Metodologi Penelitian Kualitatif. Sukabumi: CV. Jejak.

Azansyah Fakultas Ekonomi, Universitas Bengkulu; E-mail : azansyah@gmail.com. (2013). Peran Kelembagaan Dalam Perekonomian, Kondisi Pembangunan Kelembagaan Di Indonesia, Dan Membangun Lembaga Yang Efektif. EKBISI, Vol. VII, No. 2, , $262-279$.

Bayu, E. T. (2019). Strategi dan Inovasi Badan Usaha Milik Desa dalam meningkatkan Potensi dan dan Kesejahteraan Masyarakat Desa (Studi pada BUMDes Mandiri, Desa Morobakung, Kecamatan Manyar Kabupaten Gresik). Skripsi Ely, 106. 
Bharanomics

Vol. 1 No. 12020

EIma Lazuardiah dkk., Peran Badan Usaha Milik Desa (BUMDES)

Rahma Yabbar, A. H. (2016). Tata Kelola Pemerintah Desa Dari Peraturan Di Desa Hingga Pengelolaan Badan Usaha Milik Desa Dari Perencanaan Pembangunan Desa Hingga Pengelolaan Keuangan Desa. Surabaya: Penerbit Pustaka.

Undang-Undang Republik Indonesia Nomor 32 Tahun 2004 tentang Pemerintah Daerah Undang-Undang Nomor 11 Tahun 2009 tentang Kesejahteraan Sosial.

Undang-Undang Republik Indonesia Nomor 6 Tahun 2014 tentang Desa. 